\title{
Chloroquine resistance is associated to multi-copy pvcrt-o gene in Plasmodium vivax malaria in the Brazilian Amazon
}

\author{
Siuhelem Rocha Silva ${ }^{1,2}$, Anne Cristine Gomes Almeida ${ }^{1,2}$, George Allan Villarouco da Silva', \\ Rajendranath Ramasawmy ${ }^{1,2}$, Stefanie Costa Pinto Lopes ${ }^{1,5}$, André Machado Siqueira ${ }^{1,3}$, \\ Gabriel Luíz Costa ${ }^{4}$, Taís Nóbrega Sousa ${ }^{4}$, José Luiz Fernandes Vieira ${ }^{6}$, Marcus Vinícius Guimarães Lacerda ${ }^{1,5}$, \\ Wuelton Marcelo Monteiro ${ }^{1,2}$ and Gisely Cardoso de Melo ${ }^{1,2^{*}}$
}

\begin{abstract}
Background: The resistance of Plasmodium vivax to chloroquine has become an obstacle to control strategies based on the use of anti-malarials. The current study investigated the association between $P$. vivax CQ-resistance in vivo with copy number variation and mutations in the promoter region in pvcrt-o and pvmdri genes.

Methods: The study included patients with P. vivax that received supervised treatment with chloroquine and primaquine. Recurrences were actively recorded during this period.

Results: Among the 60 patients with P. vivax, 25 were CQ-resistant and 35 CQ-susceptible. A frequency of 7.1\% of multi-copy pvcrt-o was observed in CQ-susceptible samples and 7.7\% in CQ-resistant at D0 (P>0.05) and 33.3\% in CQresistant at DR ( $\mathrm{P}<0.05)$. For pvmdr1, 10.7\% of the CQ-susceptible samples presented multiple copies compared to $11.1 \%$ in CQ-resistant at D0 and 0.0\% in CQ-resistant at DR ( $P>0.05)$. A deletion of $19 \mathrm{bp}$ was found in 11/23 (47.6\%) of the patients with CQ-susceptible P. vivax and 3/10 (23.1\%) of the samples with in CQRPv at D0. At day DR, 55.5\% of the samples with CQRPv had the $19 \mathrm{bp}$ deletion. For the pvmdr-1 gene, was no variation in the analysed gene compared to the P. vivax reference Sal-1.

Conclusions: This was the first study with 42-day clinical follow-up to evaluate the variation of the number of copies and polymorphisms in the promoter region of the pvcrt-o and pvmdr1 genes in relation to treatment outcomes. Significantly higher frequency of multi-copy pvcrt-o was found in CQRPv samples at DR compared to CQ-susceptible, indicating parasite selection of this genotype after CQ treatment and its association with CQ-resistance in vivo.
\end{abstract}

\section{Background}

Malaria remains a major public health problem in many countries. Globally, 3.2 billion people are exposed to its transmission in 91 countries and territories around the world. In 2016, an estimated 216 million cases of malaria occurred worldwide. About $4 \%$ of estimated cases globally are caused by Plasmodium vivax [1]. In some countries, such as Brazil, the current treatment for $P$. vivax is

\footnotetext{
*Correspondence: cardosogisely@gmail.com

1 Fundação de Medicina Tropical Dr. Heitor Vieira Dourado, Manaus, Amazonas 69040-000, Brazil

Full list of author information is available at the end of the article
}

based on two anti-malarials, chloroquine $(\mathrm{CQ})$ and primaquine $(\mathrm{PQ})[2]$. One of the greatest threats to the control and elimination of malaria is the spread of parasites resistant to anti-malarial drugs. Plasmodium vivax resistance to chloroquine (CQRPv) is difficult to detect due to the low level of parasitaemia among parasite carriers and also to distinguish from relapses to reinfections [3].

The first reports of CQRPv were from 1989 [3, 4], 30 years after the resistance report for Plasmodium falciparum. In Brazil, the first reported case of CQRPv was from a patient treated in Manaus, in the Brazilian Amazon [5]. In this city, other subsequent studies assessed the efficiency of standard supervised therapy and the 
proportion of CQ treatment failures was $10.1 \%$ in 2007 [6] and 5.2\% in 2014 [7].

pfcrt-o and pfmdr 1 are molecular markers involved in CQ resistance in P. falciparum [8]. Several studies sought mutations in these genes orthologs in $P$. vivax samples and the majority did not show the involvement of these genes with CQ resistance $[9,10]$, suggesting that in this species the mechanism is probably different. In an in vivo study, in Manaus, $P$. vivax isolates from patients treated with CQ with treatment failure presented an increased pvcrt-o and pvmdr-1 gene expression on both D0 (day of admission) and DR (day of recrudescence) compared to patients that responded properly to treatment. No significant differences were observed between immature and mature asexual forms in CQRPv and susceptible groups [11]. Other study cited that pvcrt-o transcription is not a primary determinant of ex vivo drug susceptibility, but is rather related to stage of parasite development [12].

An AAG insertion in the exon I of pvcrt-o gene leading to an extra amino acid at position 10 (termed K10 insertion) was identified as a possible marker for CQRPv [13]. In Myanmar, more than half of the samples (63.9\%) showed the K10 insertion [14]. During later years there have been an increasing number of whole genome sequences for $P$. vivax from Latin America where polymorphisms in potential drug resistance genes are mentioned $[15,16]$. These studies showed that the genetic basis of drug resistance can be gained simply by examining the genomes of parasites.

This study aimed to investigate the association between CQRPv with copy number variation and mutations in the promoter region in $p v c r t-o$ and $p v m d r 1$.

\section{Methods}

\section{Ethics statement}

The study was approved by the Ethics Review Board of Fundação de Medicina Tropical Dr. Heitor Vieira Dourado (FMT-HVD) (approval number 426/2011). Participants were informed about the study and signed a consent form. In the case of under 18 years, the study participant signed an assent form and the guardians signed a consent form.

\section{Location of the study}

The study was conducted from January 2012 to April 2013 at the FMT-HVD, an infectious disease referral centre located in Manaus, in the Western Brazilian Amazon.

\section{Selection of patients}

The study included patients with $P$. vivax malaria of both genders, aged 6 months -60 years, weight greater than $5 \mathrm{~kg}$, with blood parasite density from 250 to 100,000 parasites $/ \mathrm{mL}$ and axillary temperature $\geq 37.5^{\circ} \mathrm{C}$ or history of fever in the last $48 \mathrm{~h}$. Use of anti-malarials in the previous 30 days, impossibility to be followed up for 42 days and clinical complications were considered exclusion criteria [17]. Patients received supervised treatment with $25 \mathrm{mg} /$ $\mathrm{kg}$ of CQ phosphate over a 3-day period $(10 \mathrm{mg} / \mathrm{kg}$ on days 0 and $7.5 \mathrm{mg} / \mathrm{kg}$ on days 1 and 2 . PQ was prescribed at the end of follow-up or if malaria recurred during follow-up, at the dosage of $0.5 \mathrm{mg} / \mathrm{kg}$ per day, during 7 days.

Patients were evaluated on days $0,1,2,3,7,14,28$ and 42 and, if they felt ill, at any time during the follow-up period. Day 0 (D0) is defined as the admission day and day of recurrence (DR) as the day of recrudescence for the same patient. Both samples from the same patient were analysed whenever available. For some patients, only a one-time sample (D0 or DR) was available. Thick blood smears and full blood counts were collected from all patients on each visit. On D0 and in DR, whole blood was also collected for DNA storage. CQ and desethylchloroquine (DCQ) plasmatic levels were determined only in case of parasitological failure. Three aliquots of $100 \mu \mathrm{L}$ of plasma from DR samples were spotted onto filter paper for later analysis by high performance liquid chromatography to determine the levels of CQ and DCQ, as previously described $[2,18]$. CQRPv was defined as a parasite recurrence presenting plasma concentrations of CQ plus DCQ higher than $100 \mathrm{ng} / \mathrm{mL}$ when added up. Susceptible-CQ $P$. vivax group consisted of patients with no parasite recurrence during the follow-up period.

\section{Plasmodium vivax diagnosis}

Thick blood smear was performed by the Walker technique [19] and evaluated by an experienced microscopist. Parasite densities were calculated by counting the number of parasites per 500 leukocytes and the number of parasites/ $\mu \mathrm{L}$ per patient was determined [20]. Real-time PCR was performed to confirm $P$. vivax monoinfection. The extraction of total DNA from whole blood was performed using the QIAamp DNA Blood Mini Kit (Qiagen, USA), according to the manufacturer's protocol. The DNA was amplified in an Applied Biosystems 7500 Fast System using primers and TaqMan fluorescence labeled probes for real-time PCR [21].

\section{Copy number variation of pvcrt-o and pvmdr-1}

Quantitative PCR (qPCR) was performed using Taqman ${ }^{\circledR}$ Universal PCR Master Mix (Applied Biosystems) and 100-200 ng of template DNA were prepared from each sample. PCR products were amplified and identified on a 7500 FAST (Applied Biosystems). Sequences of primers used to determine copy number variation of pvcrt-o [22] and pvmdr-1 [23] genes were described in Additional file 1. 
Cycling parameters for PCR were an initial denaturation step at $95{ }^{\circ} \mathrm{C}$ for $10 \mathrm{~min}, 40$ cycles of $15 \mathrm{~s}$ at $95{ }^{\circ} \mathrm{C}$ and $1 \mathrm{~min}$ at $60{ }^{\circ} \mathrm{C}$. The single-copy $\beta$-tubulin gene was used as a reference gene (normalizer), and a field sample with a single copy of the target gene was used as a calibrator. The $\Delta \Delta \mathrm{Ct}$ method was used to determine the number of copies of pvcrt-o and pvmdr-1 genes relative to a standard calibrator sample. Samples were considered to have a single copy of the gene when the estimated value was $0.5-1.5$, while values above 1.5 were defined as gene amplification. Each DNA sample was assayed in triplicate.

To define the calibrators for copy number variation (CNV) analysis using real-time PCR assays, plasmids containing a single copy of each gene: pvcrt-o, pvmdr1 and pvtubulin were constructed. The presence of a unique copy of each gene was confirmed by sequencing. Using the single-copy plasmids, a set of field samples to define the gene copy number using relative quantification in real-time PCR was evaluated. Thus, samples with a single copy of $p v c r t-o$ and $p v m d r-1$ were selected to be used as calibrators in the $\mathrm{CNV}$ assays.

\section{Nucleotide sequencing of the promoter region of $p v c r t-o$ and pvmdr-1 genes}

PCR primers and different reaction conditions used to amplify $p v c r t-o$ and $p v m d r-1$ gene sequences are described in Additional file 2. Sequencing reaction was performed in triplicate. Nucleotide sequences were analysed using the NCBI BLAST algorithm and compared with reference sequences of GenBank [24]. Amino acid sequences were aligned and compared with sequences of the reference chloroquine transporter from $P$. vivax Sal1 (GeneBank ID: NC_009906) using Geneious ${ }^{\circledR}$ software (Biomatters, v6.0.5).

\section{Polymorphism analysis of msp1F3, MS2 and MS8 molecular markers for patients with CQRPv}

For the genotyping procedures for comparing day 0 and recurrences samples, 3 highly polymorphic genes were chosen according to diversity and discriminatory potential in the region, msp1F3, MS2, and MS8 [25, 26]. PCRs were performed in $20 \mu \mathrm{L}$ reactions with $10 \mu \mathrm{M}$ of each primer, $2 \mu \mathrm{L}$ of $10 \times$ Buffer B $(50 \mathrm{mM} \mathrm{KCl}, 10 \mathrm{mM}$ Tris, $\mathrm{pH} 8.3$ ), $2.5 \mathrm{mM}$ each dNTP, $25 \mathrm{mM} \mathrm{MgCl} 2,1.5 \mathrm{U}$ Taq DNA polymerase and $5 \mu \mathrm{L}$ genomic DNA, as described in Additional file 3. All reagents were used from Invitrogen. $3 \mu \mathrm{L}$ of diluted primary PCR product was used as template for the nested PCR. PCRs were performed with conditions as follows: initial denaturation at $95{ }^{\circ} \mathrm{C}$ for $1 \mathrm{~min}$, followed by 29 cycles (primary PCR) or 24 cycles (nested PCR) of denaturation at $95^{\circ} \mathrm{C}$ for $30 \mathrm{~s}$, annealing at $59{ }^{\circ} \mathrm{C}$ for $45 \mathrm{~s}$, elongation at $72{ }^{\circ} \mathrm{C}$ for $1 \mathrm{~min}$, followed by a final elongation at $72{ }^{\circ} \mathrm{C}$ for $5 \mathrm{~min}$. PCR products were sent to Macrogen for capillary electrophoresisbased sequencing and analysed with Gene Marker version 2.6.0. To distinguish reinfection, recrudescence, and relapse by $P$. vivax, was used the classification method recommended by WHO for $P$. falciparum [27]. For each recurrence, samples were classified as homologous if at least 1 allele for each locus investigated was detected in both paired samples (D0 and DR) on two different markers and as heterologous if all alleles for a given marker were different on two or more markers [11].

\section{Statistical analyses}

Data were analysed using SPSS $^{\circledR}$ version 21.0 for Windows (SPSS Inc. ${ }^{\circledR}$ Chicago, IL, USA). Normal distribution of data was evaluated with the Kolmogorov-Smirnov test. Asexual parasitaemia at D0, D1, D2 and D3 was compared in patients with CQRPv and CQ-susceptible $P$. vivax using T-Student test. Parasitaemia clearance rates at D1, D2 and D3 were compared in patients with CQRPv and CQ-susceptible P. vivax using Chi square or Fisher's test. Chi square or Fisher's test was used to test differences in proportions of polymorphism of the promoter region and copy number variation. A $p$ value of 0.05 or lower was considered to be statistically significant. The genetic variation for each microsatellite locus was measured by calculating the expected heterozygosity $\left(\mathrm{H}_{\mathrm{E}}\right) . \mathrm{H}_{\mathrm{E}}$ was calculated using D0 and DR for each locus as $=[n /(n-1)]\left[1-\sum p_{i}^{2}\right]$ where $n$ is the number of isolates sampled and $\mathrm{p}_{\mathrm{i}}$ is the frequency of allele $\mathrm{i}$.

\section{Results}

Sixty patients with $P$. vivax were included in the study. Twenty-five patients presented CQRPv and 35 presented CQ-susceptible P. vivax. Clinical and laboratory characteristics of the patients with CQRPv and CQ-susceptible $P$. vivax are presented in Tables 1,2 . Of the patients with CQRPv, $80 \%$ were male, with a mean age of 24.6 years. The mean haemoglobin was $12.8 \mathrm{~g} / \mathrm{dL}$ at D0 and $12.6 \mathrm{~g} /$ $\mathrm{dL}$ at $\mathrm{DR}$. The geometric mean parasitaemia was 2553.5 parasites $/ \mathrm{mm}^{3}$ at D0 and 4672.1 parasites $/ \mathrm{mm}^{3}$ at DR (Table 2). The mean blood levels of CQ plus DCQ were higher than $100 \mathrm{ng} / \mathrm{mL}$ in all patients with recurrent infection. Thirty-five patients with CQ-susceptible $P$. vivax were randomly selected and included as controls (Table 2). Of the patients with CQ-susceptible P. vivax, $77.2 \%$ were males, mean age of 33.1 years. The mean haemoglobin was $13.2 \mathrm{~g} / \mathrm{dL}$. The geometric mean parasitaemia was $2623.9 / \mathrm{mm}^{3}$.

Asexual parasitaemia mean was similar at D0, D1, D2 and D3 in patients with CQRPv and CQ-susceptible $P$. $\operatorname{vivax}(\mathrm{P}>0.05)$. At $\mathrm{D} 1$, parasitaemia cleared in 2.9 and $0 \%$ of the patients with CQRPv and CQ-susceptible P. vivax, 
Table 1 Demographic and clinical characteristics of the study CQRPv admitted to a tertiary health centre, Manaus, Amazon, Brazil

\begin{tabular}{|c|c|c|c|c|c|c|}
\hline Code & Sex/age & DR & $\begin{array}{l}\text { Haemoglobin level } \\
\text { in D0 }\end{array}$ & $\begin{array}{l}\text { Haemoglobin level } \\
\text { in DR }\end{array}$ & $\begin{array}{l}\text { Asexual malarial } \\
\text { parasites/ } \mu \mathrm{L} \text { in D0 }\end{array}$ & $\begin{array}{l}\text { Asexual malarial } \\
\text { parasites } / \mu \mathrm{L} \text { in } \mathrm{DR}\end{array}$ \\
\hline R1 & $M / 38$ & D28 & 12.7 & 14.1 & 1013.8 & 660.0 \\
\hline R2 & $M / 1$ & D23 & 11.1 & 8.9 & 1000.0 & 8281.2 \\
\hline R3 & $\mathrm{M} / 40$ & D31 & 16.4 & 16.2 & 6901.0 & 281.4 \\
\hline R4 & $M / 2$ & D28 & 10.7 & & 5776.0 & $10,105.8$ \\
\hline R5 & $M / 35$ & D34 & 14.7 & 14.5 & 2105.6 & 2853.60 \\
\hline R6 & $\mathrm{M} / 8$ & D31 & 9.4 & 10.0 & 1136.8 & 4968.0 \\
\hline R7 & $M / 46$ & D31 & 12.9 & 12.0 & 5059.2 & 4160.0 \\
\hline R8 & $F / 21$ & D29 & 13.9 & 12.1 & 116.0 & 614.2 \\
\hline R9 & $F / 21$ & D28 & 12.4 & 12.3 & $13,691.7$ & 180.0 \\
\hline R10 & $F / 43$ & D34 & 13.6 & 13.1 & 676.8 & 2613.2 \\
\hline R11 & $M / 48$ & D30 & 14.9 & 14.7 & $21,285.0$ & 10.0 \\
\hline R12 & $\mathrm{M} / 54$ & $\mathrm{D} 27$ & 14.0 & 15.1 & 343.0 & 154.8 \\
\hline R13 & $F / 8$ & D32 & 10.2 & 9.5 & 690.0 & 2278.0 \\
\hline R14 & $M / 22$ & D34 & 13.4 & 12.5 & 4347.0 & 6871.0 \\
\hline R15 & $M / 41$ & D36 & 14.2 & 13.5 & 686.0 & 436.8 \\
\hline R16 & $\mathrm{M} / 41$ & D34 & 14.4 & 12.8 & 105.8 & 4507.7 \\
\hline R17 & $M / 13$ & D38 & 12.4 & 12.0 & 2582.1 & 2613.2 \\
\hline R18 & $M / 16$ & D32 & 13.5 & 12.9 & 78.0 & $11,096.2$ \\
\hline R19 & $M / 44$ & D31 & 12.2 & 14.0 & 8272.0 & 3162.0 \\
\hline R20 & $M / 26$ & D25 & 15.1 & 15.6 & 1974.7 & 5385.6 \\
\hline R21 & $M / 38$ & D28 & 14.0 & 14.4 & 2548.0 & 150.0 \\
\hline R22 & $M / 1$ & D22 & & 10.2 & 1380.0 & $21,360.0$ \\
\hline R23 & M/05 & D28 & 11.4 & 10.0 & 4560.0 & $22,440.0$ \\
\hline R24 & $\mathrm{M} / 5$ & D27 & 9.4 & 11.8 & 3120.0 & 1380.0 \\
\hline R25 & $F / 21$ & D26 & 11.3 & 11.6 & 990.0 & 240.0 \\
\hline
\end{tabular}

$D O$ day admission, $D R$ day of recrudescence, $M$ male, $F$ female

Table 2 Clinical characteristics of the study participants CQRPv and susceptible-chloroquine $P$. vivax admitted to a tertiary health centre, Manaus, Amazon, Brazil

\begin{tabular}{|c|c|c|c|c|c|c|}
\hline & Resistant D0 (\%) & IC $95 \%$ & Resistant DR (\%) & IC $95 \%$ & Susceptible (\%) & IC $95 \%$ \\
\hline \multicolumn{7}{|l|}{ Gender } \\
\hline Male & $20(80.0)$ & - & - & - & $27(77.2)$ & - \\
\hline Female & $5(20.0)$ & - & - & - & $8(22.8)$ & - \\
\hline Age (mean) & 24.6 & $17.8-32.0$ & - & - & 33.1 & $28.5-37.6$ \\
\hline Asexual malaria parasites/ $\mu \mathrm{L}$ & 2553.5 & $1343.2-3763.8$ & 4672.1 & $2214.0-7130.22$ & 2623.9 & 1993.0-3254.7 \\
\hline Haemoglobin (mean) & 12.8 & $12.1-13.6$ & 12.6 & $11.9-13.4$ & 13.2 & $12.7-13.7$ \\
\hline Chloroquine concentrations (ng/mL) & - & - & 230.1 & $182.8-276.1$ & - & - \\
\hline
\end{tabular}

D0 day admission, $D R$ day of recrudescence

respectively $(\mathrm{P}=0.659) ; 47$ and $59.1 \%$ of the patients with CQRPv and CQ-susceptible $P$. vivax cleared at $\mathrm{D} 2$, respectively $(\mathrm{P}=0.274)$; and 85.3 and $81.8 \%$ of the patients with CQRPv and CQ-susceptible $P$. vivax cleared at $\mathrm{D} 3$, respectively $(\mathrm{P}=0.225)$.
For the microsatellite analysis at MS1F3, MS2 and MS8 loci, reading of the alleles was successful in 21 of the $25 \mathrm{CQRPv}$ samples analysed. In these samples, $86.0 \%$ presented at least one concordant allele in primary infection and recrudescence (Additional file 4). The expected heterozygosity $\left(\mathrm{H}_{\mathrm{E}}\right)$ for msp1F3 was: 0.880 at D0 and 0.780 at DR; for MS2, 0.960 at D0 
and 0.940 at DR; and for MS8 was 1.00 at D0 and 0.970 at DR.

\section{Analysis of copy number variation of the pvcrt-o and pvmdr1 genes}

For pvcrt-o CNV analysis, with 28 patients with CQsusceptible $P$. vivax and 25 patients with CQRPv being analysed (14 samples from D0 to 18 from DR). At D0, $7.1 \%$ of the CQ-susceptible $P$. vivax presented multiple copies of pvcrt-o, $7.7 \%$ of the CQRPv showed multiple copies of pvcrt-o at D0 while at DR 33.0\% had multiple copies of pvcrt-o (Fig. 1a). There was a significant difference between CQ-susceptible P. vivax and CQRPv at DR $(\mathrm{P}=0.02)$.

For pvmdr-1 CNV analysis, a total of $28 \mathrm{CQ}$-susceptible and 25 CQRPv (9 from D0 to 17 from DR) P. vivax samples were analysed. It was verified that $10.7 \%$ of the CQ-susceptible $P$. vivax samples, $11.1 \%$ of the CQRPv samples at D0 and $0.0 \%$ of the CQRPv samples at DR presented multiple copies (Fig. 1b). There was no significant difference between CQ-susceptible and CQRPv groups regarding pvmdr-1 CNV $(\mathrm{P}>0.05)$. Samples that did not meet the criteria used in the methodology were excluded from the analysis of these genes. Overall, $p v m d r 1$ and pvcrt-o CNV was not related to parasitaemia and age for individuals infected with $P$. vivax with either with multiple copies of $p v m d r-1$ or with one copy of the genes $(\mathrm{P}>0.05)$.

\section{Analysis of pvcrt-o and pvmdr1 genes polymorphisms in the promoter region}

Nucleotide sequencing of a region flanking the promoter and exon I of the gene pvcrt-o showed a deletion of $19 \mathrm{bp}$ in the promoter region at position 32,083-32,102 and an insertion of three bases in exon 1 leading to 5AAG repeats (AAG) after codon nine, leading to the K10 insertion compared to the reference sequence NC_009906Chloroquine resistance transporter-P. vivax Sal1, with 4AAG repeats termed wild type here (Fig. 2).

A deletion of $19 \mathrm{bp}$ was found in $11 / 23$ (47.6\%) of the patients with CQ-susceptible P. vivax and 3/10 (23.1\%) of the samples with in CQRPv at D0. At day DR, 55.5\% of the samples with CQRPv had the $19 \mathrm{bp}$ deletion. There was no significant difference between groups $(P \geq 0.05$, Fisher's exact test) (Table 3).
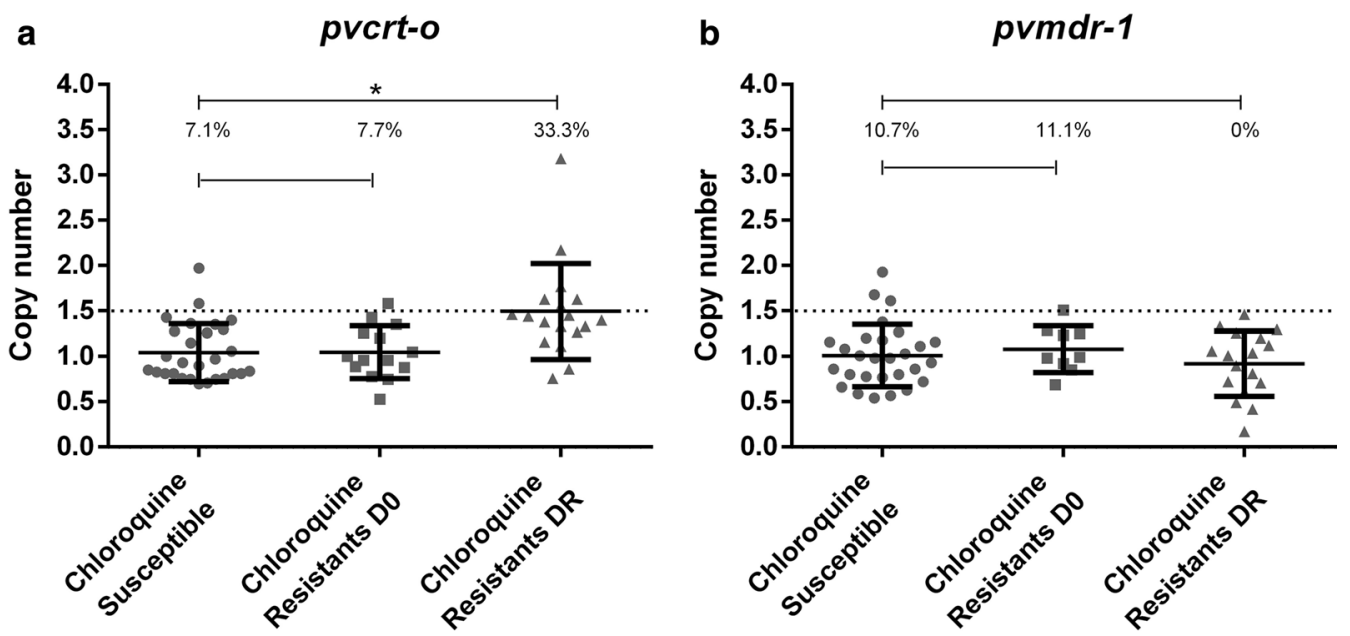

Fig. 1 Determination of the copy number variation of genes in CQ-susceptible and patients resistant. a Determination of the number of copies for the pvcrt-o gene between the susceptible and resistant groups in D0 and DR. $\mathbf{b}$ Determination of the number of copies of the pvmdr-1 gene between the susceptible and resistant groups in D0 and DR. ${ }^{*} \mathrm{P}<0.05$

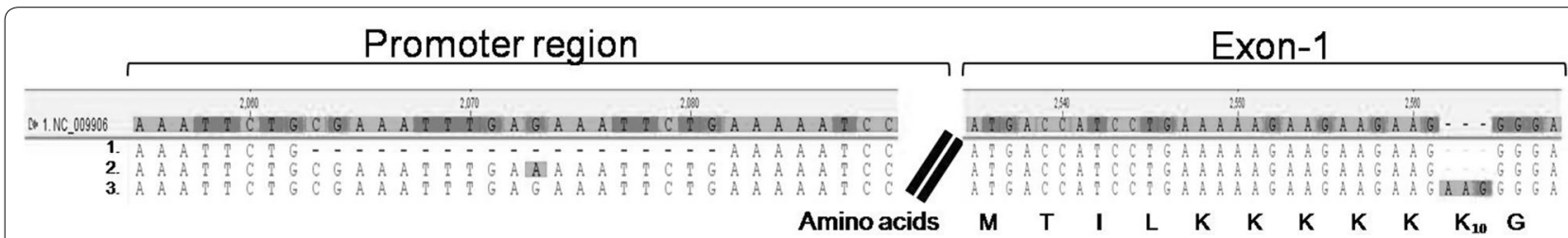

Fig. 2 Scheme of the pvcrt-o gene showing promoter region and exon 1. This figure show specimens with $19 \mathrm{~kb}$ deletion without $\mathrm{K} 10 \mathrm{insertion}$ (1), samples with $19 \mathrm{~kb}$ insertion without $\mathrm{k} 10$ insertion (2) and samples with $19 \mathrm{~kb}$ insert with $\mathrm{k} 10$ insertion (3) 
All the samples with 19 bp deletion presented 4AAG repeats in the exon I (Table 2). Of the samples with wild type sequence, 8 (33.3\%), 8 (60.0\%) and $3(25.0 \%)$ exhibited 5AAG (K10) repeats in the exon I of the gene in the samples with CQ-susceptible $P$. vivax, CQRPv at D0 and $\mathrm{CQRPv}$ at DR, respectively (Table 3 ).

For the $p v m d r-1$ gene, nucleotide sequencing was performed in 66 samples. Sixteen samples with CQ susceptible $P$. vivax and $23 \mathrm{CQRPv}$ were sequenced, 14 in the D0 and 9 in the DR. There was no variation in the analysed gene compared to the $P$. vivax reference Sal- 1 available in the NCBI gene bank.

\section{Discussion}

Chloroquine and PQ are still the drugs of choice for the treatment of $P$. vivax in some countries, especially in Latin America [28-31]. However, CQRPv has emerged in several parts of the world [32, 33], including Malaysia [30], Myanmar [34], India [33] and Brazil [7, 35]. The molecular mechanism of CQRPv is still not well defined. In this study, CNV of pvcrt-o and pvmdr1 was determined in patients with CQRPv from a well-characterized cohort under supervised treatment and this demonstrated a relationship between CQRPv in vivo and increased CNV of the pvcrt-o. These patients presented an effective concentration of CQ and DCQ and microsatellite revealed the presence of the same clonal nature at D0 and DR, indicating recrudescence. In Brazil, for the first time, CNV of the pvcrt-o was evaluated and the amplification of this gene was observed in $P$. vivax isolates in a study with treatment supervised for 42 days (Table 3).

In regions where mefloquine (MQ) is used to treatment of $P$. falciparum infection, drug pressure mediated by increase copy number variation of $p v m d r 1$ may select MQ-resistant $P$. vivax [36]. Actually, some studies show that $p v m d r 1$ amplification was associated to MQresistance [13, 23, 37, 38]. MQ was used in the Brazilian Amazon in the early 2000s, possibly contributing to the selection of this genotype in this region [5].

In this study, pvmdr-1 CNV was not associated to CQRPv. Although CQ was found to be effective in India $[39,40]$, amplification of the $p v m d r-1$ gene was found in $31.6 \%$ of the Indian isolates [33]. In Brazil, two studies described $p v m d r 1$ copy number variation, with an amplification rate of $0.9 \%$ in isolates from Acre state [41] and $20 \%$ in isolates from the states of Mato Grosso and Rondônia [22]. However, these studies did not have clinical follow-up to confirm CQRPv. Pvmdr1 Y976F mutation was found in malaria-endemic regions where $C Q$ is used as the first-line treatment $[13,38,42]$.

In previous investigations, $\mathrm{CQRPv}$ isolates have shown high expression of $p v c r t-o$ and/or $p v m d r-1$ genes in a malaria reference centre in the Brazilian Amazon [11]. The main factor involved in gene expression regulation is its promoter, since it contains the binding sites for the RNA polymerases responsible for gene transcription [43]. To better elucidate CQRPv, the presence of mutations in the promoter region of the pvcrt-o and pvmdr1 genes in CQ-susceptible $P$. vivax and $\mathrm{CQRPv}$ was investigated. For the pvcrt-o gene, an deletion 19 bp sequence was found in the promoter sequence, followed by 4AAG in the exon I. Although there was no significant difference in the frequency of mutations between these two groups, the CQRPv presented higher frequency of the deletion of 19 bp at D0 compared to at DR.

Here, we also described the occurrence of the wild type sequence in pvcrt-o, followed by 5AAG repeat (K10 insert) in CQ-susceptible P. vivax and CQRPv, with a frequency ranging from 25 to $60 \%$. Similar frequency of

Table 3 Frequency of the mutation and repetition AAG in the promoter region of the pvcrt-o gene in CQRPV and CQ susceptible $P$. vivax

\begin{tabular}{lcccc}
\hline & Susceptible (\%) & Resistant in D0 (\%) & $\mathbf{p}$ & Resistant in DR (\%) \\
\hline $\begin{array}{l}\text { Deletion 19 pb } \\
\text { Yes }\end{array}$ & $11(47.6)$ & $3(23.1)$ & & \\
No & $12(52.4)$ & $10(76.9)$ & 0.152 & $6(55.5)$ \\
Deletion 19 pb (4AAG) & & & $5(44.5)$ \\
Yes & $11(47.6)$ & $3(23.1)$ & 0.152 & $6(55.5)$ \\
No & $12(52.4)$ & $10(76.9)$ & & $5(44.5)$ \\
Wild type (4AAG) & & & & 0.690 \\
Yes & $2(11.1)$ & $1(10.0)$ & & $1(12.5)$ \\
No & $21(88.9)$ & $11(90.0)$ & & $10(87.5)$ \\
Wild type (5AAG) & & $8(60.0)$ & 0.172 & $3(25.0)$ \\
Yes & $8(33.3)$ & $5(40.0)$ & & $8(75.0)$ \\
No & $15(66.7)$ & & & 0.919 \\
\hline
\end{tabular}


insertion was reported by in vitro susceptibility to CQ studies using isolates from Thailand (46\%) and Myanmar (56\%) [13]. More recent studies have also demonstrated K10 insertion in isolates of $P$. vivax from India [32, 33] and Ethiopia [44], but the frequency was lower than that found in our study. Among the samples from India, a high frequency of polymorphisms in the pvcrt-o and pvmdr1 genes has been demonstrated also, indicating the circulation of strains that may acquire CQRPv phenotype in that region [32, 33].

A limitation of this study is the small number of samples, restricting the possibility of detecting differences. Polyclonal infections were present, challenging the discrimination of recrudescence from relapse to re-infection. However, it was shown that plasma levels of CQ plus DCQ were higher than the minimum effective limits at DR for all patients. Results from in vivo studies, as the presented in this study, are very useful since they provide the response to treatment in the real life, but are subject to host immune influence, drug metabolism variations and drug quality [42]. Ex vivo assays evaluate drug activity in the absence of host confounding factors [45]. Then, potential influence of host immunity can not be discarded here.

\section{Conclusions}

This was the first study with 42-day clinical follow-up to evaluate the variation of the number of copies and polymorphisms in the promoter region of the pvcrt-o and pvmdr1 genes in relation to treatment outcomes. Significantly higher frequency of multi-copy pvcrt-o was found in CQRPv samples at DR compared to CQ-susceptible, indicating parasite selection of this genotype after CQ treatment and its association with CQ-resistance in vivo.

\section{Additional files}

Additional file 1. Oligonucleotide primers used for copy number variation of P. vivax orthologs genes.

Additional file 2. Oligonucleotide primers used for promotor region sequencing of $P$. vivax orthologs genes.

Additional file 3. Oligonucleotide primers used for genotyping of P. vivax.

Additional file 4. Infection haplotypes in patients with CQRPV.

\section{Authors' contributions}

Conceived and designed the experiments: SRS GCM RS SCPL GLC TNS JLFV. Analysed the data: SRS GCM. Wrote the paper: SRS GCM ACGA WMM MVGL. Acquisition of data: GCM AMS. Critical revision of the manuscript: GCM WMM AMS SCPL MVGL. All authors read and approved the final manuscript.

\section{Author details}

1 Fundação de Medicina Tropical Dr. Heitor Vieira Dourado, Manaus, Amazonas 69040-000, Brazil. ${ }^{2}$ Universidade do Estado do Amazonas (UEA), Manaus, Amazonas 69040-000, Brazil. ${ }^{3}$ Instituto Nacional de Infectologia, Evandro Chagas, Fiocruz, Rio de Janeiro 21040-360, Brazil. ${ }^{4}$ Centro de Pesquisas René Rachou,
Fiocruz, Belo Horizonte, Minas Gerais 30190-002, Brazil. ${ }^{5}$ Instituto Leônidas \& Maria Deane (ILMD), Fiocruz, Manaus, Amazonas 69057-070, Brazil. ${ }^{6}$ Universidade Federal do Pará, Belém, Pará 66010-010, Brazil.

\section{Acknowledgements}

We acknowledge Nélida Teresa Sánchez Rúa, Maria Raimunda Costa for sample collection and Sequencing Platform of the Instituto Leônidas \& Maria Deane.

\section{Competing interests}

The authors declare that they have no competing interests.

\section{Availability of data and materials}

The datasets during and/or analysed during the current study available from the corresponding author on reasonable request.

\section{Ethics approval and consent to participate}

The study was approved both by the Research Ethics Committee of the Fundação de Medicina Tropical Dr. Heitor Vieira Dourado (FMT-HVD) and by the National Commission for Research Ethics (CONEP) under opinion $426 / 2011$

\section{Funding}

Research Support Foundation of Amazonas (FAPEAM) through PPSUS (protocol 062.00650.2014) and Guyamazon (protocol 26873.

UNI554.3814.29062015) project supported this study. MVGL are level 1 fellows from CNPq. SRS have fellowships from FAPEAM. ACGA have fellowships from $\mathrm{CNPq}$

\section{Publisher's Note}

Springer Nature remains neutral with regard to jurisdictional claims in published maps and institutional affiliations.

Received: 11 May 2018 Accepted: 9 July 2018

Published online: 16 July 2018

\section{References}

1. WHO. World mlaria report 2017. Geneva: World Health Organization; 2017.

2. Naing C, Aung K, Win DK, Wah MJ. Efficacy and safety of chloroquine for treatment in patients with uncomplicated Plasmodium vivax infections in endemic countries. Trans R Soc Trop Med Hyg. 2010;104:695-705.

3. Rieckmann KH, Davis DR, Hutton DC. Plasmodium vivax resistance to chloroquine? Lancet. 1989:2:1183-4.

4. Baird JK, Basri H, Purnomo Bangs MJ, Subianto B, Patchen LC, et al. Resistance to chloroquine by Plasmodium vivax in Irian Jaya, Indonesia. Am J Trop Med Hyg. 1991;44:547-52.

5. Alecrim MdG, Alecrim W, Macedo V. Plasmodium vivax resistance to chloroquine (R2) and mefloquine (R3) in Brazilian Amazon region. Rev Soc Bras Med Trop. 1999;32:67-8.

6. de Santana Filho FS, Arcanjo AR, Chehuan YM, Costa MR, Martinez-Espinosa FE, Vieira JL, et al. Chloroquine-resistant Plasmodium vivax, Brazilian Amazon. Emerg Infect Dis. 2007;13:1125-6.

7. Marques MM, Costa MR, Santana Filho FS, Vieira JL, Nascimento MT, Brasil $\mathrm{LW}$, et al. Plasmodium vivax chloroquine resistance and anemia in the western Brazilian Amazon. Antimicrob Agents Chemother. 2014;58:342-7.

8. Lo E, Hemming-Schroeder E, Yewhalaw D, Nguyen J, Kebede E, Zemene $E$, et al. Transmission dynamics of co-endemic Plasmodium vivax and $P$. falciparum in Ethiopia and prevalence of antimalarial resistant genotypes. PLoS Negl Trop Dis. 2017;11:e0005806.

9. Nomura T, Carlton JM, Baird JK, del Portillo HA, Fryauff DJ, Rathore D, et al. Evidence for different mechanisms of chloroquine resistance in 2 Plasmodium species that cause human malaria. J Infect Dis. 2001;183:1653-61.

10. Sa JM, Yamamoto MM, Fernandez-Becerra C, de Azevedo MF, Papakrivos $J$, Naude B, et al. Expression and function of pvcrt-o, a Plasmodium vivax ortholog of pfcrt, in Plasmodium falciparum and Dictyostelium discoideum. Mol Biochem Parasitol. 2006;150:219-28. 
11. Melo GC, Monteiro WM, Siqueira AM, Silva SR, Magalhaes BM, Alencar $A C$, et al. Expression levels of pvcrt-o and pvmdr-1 are associated with chloroquine resistance and severe Plasmodium vivax malaria in patients of the Brazilian Amazon. PLoS ONE. 2014;9:e105922.

12. Pava Z, Handayuni I, Wirjanata G, To S, Trianty L, Noviyanti R, et al. Expression of Plasmodium vivax crt-o is related to parasite stage but not ex vivo chloroquine susceptibility. Antimicrob Agents Chemother. 2016;60:361-7.

13. Lu F, Lim CS, Nam DH, Kim K, Lin K, Kim TS, et al. Genetic polymorphism in pvmdr 1 and pvcrt-o genes in relation to in vitro drug susceptibility of Plasmodium vivax isolates from malaria-endemic countries. Acta Trop. 2011;117:69-75.

14. Nyunt MH, Han JH, Wang B, Aye KM, Aye KH, Lee SK, et al. Clinical and molecular surveillance of drug resistant vivax malaria in Myanmar (2009-2016). Malar J. 2017;16:117.

15. Winter DJ, Pacheco MA, Vallejo AF, Schwartz RS, Arevalo-Herrera M, Herrera $\mathrm{S}$, et al. Whole genome sequencing of field isolates reveals extensive genetic diversity in Plasmodium vivax from Colombia. PLoS Negl Trop Dis. 2015:9:e0004252

16. Flannery EL, Wang T, Akbari A, Corey VC, Gunawan F, Bright AT, et al. Next-generation sequencing of Plasmodium vivax patient samples shows evidence of direct evolution in drug-resistance genes. ACS Infect Dis. 2015;1:367-79.

17. WHO. Guidelines for the treatment of malaria. Geneva: World Health Organization; 2006

18. Ruebush TK 2nd, Zegarra J, Cairo J, Andersen EM, Green M, Pillai DR, et al. Chloroquine-resistant Plasmodium vivax malaria in Peru. Am J Trop Med Hyg. 2003;69:548-52.

19. WHO. World malaria report: 2010. Geneva: World Health Organization; 2010

20. WHO. Malaria microscopy quality assurance manual. Geneva: World Health Organization; 2016.

21. Snounou G, Viriyakosol S, Zhu XP, Jarra W, Pinheiro L, do Rosario VE, et al. High sensitivity of detection of human malaria parasites by the use of nested polymerase chain reaction. Mol Biochem Parasitol. 1993;61:315-30.

22. Costa GL, Amaral LC, Fontes CJF, Carvalho LH, de Brito CFA, de Sousa TN. Assessment of copy number variation in genes related to drug resistance in Plasmodium vivax and Plasmodium falciparum isolates from the Brazilian Amazon and a systematic review of the literature. Malar J. 2017;16:152.

23. Imwong M, Pukrittayakamee S, Pongtavornpinyo W, Nakeesathit S, Nair S, Newton $\mathrm{P}$, et al. Gene amplification of the multidrug resistance 1 gene of Plasmodium vivax isolates from Thailand, Laos, and Myanmar. Antimicrob Agents Chemother. 2008;52:2657-9.

24. BLAST. Basic Local Alignment Search Tool (BLAST: Basic Local Alignment Search Tool).

25. Beck HP, Wampfler R, Carter N, Koh G, Osorio L, Rueangweerayut R, et al. Estimation of the antirelapse efficacy of tafenoquine, using Plasmodium vivax genotyping. J Infect Dis. 2016;213:794-9.

26. de Araujo FC, de Rezende AM, Fontes CJ, Carvalho LH, de Alves Brito CF. Multiple-clone activation of hypnozoites is the leading cause of relapse in Plasmodium vivax infection. PLoS ONE. 2012;7:e49871.

27. WHO. Methods and techniques for clinical trials on antimalarial drug efficacy: genotyping to identify parasite populations: informal consultation organized by the Medicines for Malaria Venture and cosponsored by the World Health Organization. Amsterdam: World Health Organization; 2008.

28. Commons RJ, Thriemer K, Humphreys G, Suay I, Sibley CH, Guerin PJ, et al. The Vivax Surveyor: online mapping database for Plasmodium vivax clinical trials. Int J Parasitol Drugs Drug Resist. 2017;7:181-90.

29. Negreiros S, Farias S, Viana GM, Okoth SA, Chenet SM, de Souza TM, et al. Efficacy of chloroquine and primaquine for the treatment of uncomplicated Plasmodium vivax malaria in Cruzeiro do Sul, Brazil. Am J Trop Med Hyg. 2016;95:1061-8.

30. Grigg MJ, William T, Menon J, Barber BE, Wilkes CS, Rajahram GS, et al. Efficacy of artesunate-mefloquine for chloroquine-resistant Plasmodium vivax malaria in Malaysia: an open-label, randomized, controlled trial. Clin Infect Dis. 2016;62:1403-11.

31. Price RN, von Seidlein L, Valecha N, Nosten F, Baird JK, White NJ. Global extent of chloroquine-resistant Plasmodium vivax: a systematic review and meta-analysis. Lancet Infect Dis. 2014;14:982-91.

32. Bansal D, Acharya A, Bharti PK, Abdelraheem MH, Elmalik A, Abosalah S, et al. Distribution of mutations associated with antifolate and chloroquine resistance among imported Plasmodium vivax in the state of Qatar. Am J Trop Med Hyg. 2017;97:1797-803.

33. Joy S, Mukhi B, Ghosh SK, Achur RN, Gowda DC, Surolia N. Drug resistance genes: $p v c r t-o$ and pvmdr-1 polymorphism in patients from malaria endemic South Western Coastal Region of India. Malar J. 2018;17:40.

34. Htun MW, Mon NCN, Aye KM, Hlaing CM, Kyaw MP, Handayuni I, et al. Chloroquine efficacy for Plasmodium vivax in Myanmar in populations with high genetic diversity and moderate parasite gene flow. Malar J. 2017;16:281.

35. Siqueira AM, Alencar AC, Melo GC, Magalhaes BL, Machado K, Alencar Filho $A C$, et al. Fixed-dose artesunate-amodiaquine combination vs chloroquine for treatment of uncomplicated blood stage $P$. vivax infection in the Brazilian Amazon: an open-label randomized, controlled trial. Clin Infect Dis. 2017:64:166-74.

36. Auburn S, Serre D, Pearson RD, Amato R, Sriprawat K, To S, et al. Genomic analysis reveals a common breakpoint in amplifications of the Plasmodium vivax multidrug resistance 1 locus in Thailand. J Infect Dis. 2016:214:1235-42

37. Lin JT, Patel JC, Kharabora O, Sattabongkot J, Muth S, Ubalee R, et al. Plasmodium vivax isolates from Cambodia and Thailand show high genetic complexity and distinct patterns of $P$. vivax multidrug resistance gene 1 (pvmdr1) polymorphisms. Am J Trop Med Hyg. 2013;88:1116-23.

38. Suwanarusk R, Chavchich M, Russell B, Jaidee A, Chalfein F, Barends M, et al. Amplification of pvmdr 1 associated with multidrug-resistant Plasmodium vivax.J Infect Dis. 2008:198:1558-64.

39. Shalini S, Chaudhuri S, Sutton PL, Mishra N, Srivastava N, David JK, et al. Chloroquine efficacy studies confirm drug susceptibility of Plasmodium vivax in Chennai, India. Malar J. 2014;13:129.

40. Saravu K, Kumar R, Ashok H, Kundapura P, Kamath V, Kamath A, et al. Therapeutic assessment of chloroquine-primaquine combined regimen in adult cohort of Plasmodium vivax malaria from primary care centres in Southwestern India. PLOS ONE. 2016;11:e0157666.

41. del Vargas-Rodriguez RC, da Silva Bastos M, Menezes MJ, Orjuela-Sanchez P, Ferreira UM. Single-nucleotide polymorphism and copy number variation of the multidrug resistance-1 locus of Plasmodium vivax: local and global patterns. Am J Trop Med Hyg. 2012;87:813-21.

42. Suwanarusk R, Russell B, Chavchich M, Chalfein F, Kenangalem E, Kosaisavee $\mathrm{V}$, et al. Chloroquine resistant Plasmodium vivax: in vitro characterisation and association with molecular polymorphisms. PLOS ONE. 2007:2:e1089.

43. Carvalho TL, Ribolla PE, Curi RA, Mota LS. Characterization and transcriptional analysis of the promoter region of the Duffy blood group, chemokine receptor (DARC) gene in cattle. Vet Immunol Immunopathol. 2009;132:153-9.

44. Golassa L, Erko B, Baliraine FN, Aseffa A, Swedberg G. Polymorphisms in chloroquine resistance-associated genes in Plasmodium vivax in Ethiopia. Malar J. 2015:14:164.

45. Russell B, Chalfein F, Prasetyorini B, Kenangalem E, Piera K, et al. Determinants of in vitro drug susceptibility testing of Plasmodium vivax. Antimicrob Agents Chemother. 2008;52:1040-5. 